\title{
David Damrosch'un Gömülü Kitap: Gılgamış Büyük Destanının Kaybı ve Yeniden Keşfi Adlı Eserinin Kritiği
}

\author{
Timuçin Buğra EDMAN**
}

\begin{abstract}
Öz
Profesör Dr. David Damrosch Harvard Üniversitesi Karşılaştırmalı Edebiyat bölümünde görev yapmaktadır. Gömülü Kitap: Gılgamış Büyük Destanının Kaybı ve Yeniden Keşfi David Damrosch'un 2007 yılında Doğu ve Batı sentezini tarihsel süzgeçten geçirerek kaleme aldığı mühim bir eserdir. Gılgamış'ın, yoldaşı Enkidu'nun ölümü üzerine ölümsüzlük arayışına çıktığı destansı yolculukta Damrosch aslında bir yandan da şarkiyatçılık anlayışının yeni bir boyutta yorumlanmasını sağlıyor. Eserin henüz ülkemizde Türkçe’ye çevrilmiş baskısı olmamasına rağmen, özellikle Doğu Edebiyatı'nın mihenk taşlarından biri olan ve ilk İngilizce çevirisiyle birlikte Batı dünyasını alt üst eden Gılgamış Destanı'nın bilinen ve bilinmeyen yönleriyle hem gizli kahramanlarını deşifre ediyor hem de bu destana Batı filtresi haricinde bir de ötekileştirilmişler açısından bakıyor. Tarihsel ve Edebi yönlerden nesnel bir biçimde kaleme alınan bu eser, bir nevi sümen altı edilmiş gerçekleri gün yüzüne çıkarmayı hedefliyor ve bunu yaparken yer yer tarihin unutulan gerçeklerine dayanıyor. Bu çerçevede bir yandan Damrosch'un bu kitabının kritiği yapılırken, öte yandan düşünceleri mercek altına alınacak, aynı zamanda Damrosch'un düşüncelerinin yankılanışı farklı ama bir o kadar da bilinç altına 'yerleş(tiril)miş’ açılardan incelenecektir.
\end{abstract}

Anahtar Kelimeler: Gılgamış Destanı, Enkidu, David Damrosch, Gömülü Kitap

\footnotetext{
* Bu Kitabın özgün ismi The Buried Book: The Loss and Rediscovery of the Great Epic of Gilgamesh olup Türkçe çevirisi bulunmamaktadır. Kitap kritiği kapsamında gerekli çeviriler özgün metne bağlı kalınarak tarafımca yapılmıştır. ** Dr. Öğr.Üyesi Timuçin Buğra Edman İstanbul Aydın Üniversitesi Fen Edebiyat Fakültesi İngiliz Dili ve Edebiyatı Florya Merkez Kampüsü. Türkiye.

Elmek: timucinedman@outlook.com
} 


\title{
The Critique of David Damrosch's The Buried Book: The Loss and Rediscovery of the Great Epic of Gilgamesh
}

\begin{abstract}
Professor Dr. David Damrosch is a professor at Harvard University's Department of Comparative Literature. The Buried Book: The Loss and Rediscovery of the Great Epic of Gilgamesh is a significant work in which David Damrosch wrote the synthesis of East and West by filtering it through history in 2007. In the legendary journey of Gilgamesh in search of immortality after the loss of his companion Enkidu, Damrosch actually enables the interpretation of Orientalism in terms of a new dimension. Despite the fact that the work has not yet been translated into Turkish in our country, with its first translation into English shaking the Western world, it does not only decipher its secret heroes with the familiar and unknown aspects of The Epic of Gilgamesh, which is one of the cornerstones of the Eastern literature, it also takes a look into the epic through the eyes of the marginalized ones except the Western scope. This work, taken in an objective form from historical and literary perspectives, aims at bringing the facts swept under the rug to light, and while doing this, in part, is based on the forgotten facts of history. While the critique of this book by Damrosch is being made in this framework, his thoughts will be examined, and the echoes of Damrosch's thoughts will be scrutinized from different viewpoints and also from the aspects that have been engraved in the subconscious.
\end{abstract}

Keywords: The Epic of Gilgamesh, Enkidu, David Damrosch, The Buried Book. 


\section{Giriş}

Çoktan beri unutulmuş olan kitabeleri kaplamış toz birikintisinden anlaş1lacağ 1 üzere, beyhudeliğe yüz tutmuş insanoğlu hâlâ nihai bir paydada toplanmaktan acizdir. Başka bir deyişle, insanlık tarihinde birçok kez kültürel kesişmeler meydana gelmiş olsa da vakit geçtikçe ve kadim harabelerin tozu kalkmadıkça, bu harabeler eski hanedanların hayallerini yıkmayı sürdürecektir. Dolayısıyla bazı insanlar gerçeği görmektense, yalanlarla bezeli bir tarihe inanmakta 1srarcıdırlar, ne de olsa gerçekler çoğu zaman oldukça rahatsız edici olabilmektedir. Bu makalede, hakikati kurgudan, uydurma öyküleri yaşanmış olaylardan ve efsaneleri gerçek hayattan ayırmak adına, David Damrosch'un Gömülü Kitap adlı eserinde mit ve efsanelerin gerçek ile çatışmasını açılarken ortaya çıkan önermeler ve yorumlamalar doğrultusunda ilerlenecektir. Dahası, bu bulguların ebedi tabiatları üzerinde durulacaktır.

\section{Gömülü Kitap Ve Onun İnsan Tecrübesine Tarih Boyunca Yaptığı Geniş Etki}

Gılgamış Destanı'nda iki ana kahraman vardır: Gılgamış ve Enkidu. Destanın başlangıcında bu iki karakter birbirleri ile adeta birer 'esas kahraman' ve düşmanmış̧̧asına çatışma halinde olsalar da erkek savaş̧̧ıların bitmez tükenmez dayanışmasını gözler önüne seren iki yoldaş oldukları ortaya çıkar. Aralarındaki ilişki öyledir ki, ikisi de birbirinin kusurunu örter ve biri olmadan diğeri de olamaz. Bir diğer bakışla, birbirlerinin zıtlıkları aslında hem birbirlerini tamamlayan hem de birbirlerini yok eden özellikleridir. Bu tip zıtlıkların mücadelesi aslında bizi Antik Yunan Dünyasının İyonya felsefesine götürecektir. Anaksimandros, dünyanın sırasıyla zıtlıklardan meydana geldiğini ve bu zitlıkların muntazaman dünyaya veya evrene hükmederek sonunda ortadan kalktıklarını iddia etmiştir. İlkçağ Felsefe Tarihi adlı eserinde Ahmet Arslan (2017) Anaksimandros'un sözlerini şöyle aktarmaktadır: "Var olan şeylerin ilkesi, aperion'dur. Şeyler ondan meydana gelir ve yine zorunlu olarak onda ortadan kalkarlar; çünkü onlar zamanın sırasına uygun olarak birbirlerine karşı işlemiş oldukların haksızlıkların cezasını 
(kefaretini) öderler" (s.98-99). Peki bu aperion olgusundan nereye varabiliriz? Bunun Gılgamış Destanı ile ne gibi bir bağlantısı vardır? Bu zıtlıkların evreni meydana getirdiğinin Batı kaynaklı düşüncesini ortaya atan Anaksimandros İÖ 610 ile 547 yılları arasında yaşadığ 1 varsayılan batılı bir düşünürdür. Gılgamış Destanı'nın ise C4 karbon testlerine dayanarak tahmini olarak İÖ 2150-1400 (bu konuda çok farklı tarihler bulunmaktadır) tarihleri arasında yazıldığ 1 öngörülmektedir (Mark, 2018). Şu hâlde evrenin zitlıklardan oluştuğunu ve birbirlerini dengelediklerini ortaya atan bu felsefi yaklaşım bir edebi eser olarak karşımıza çıkmaktadır. Bu düşünüşün benzeri olan Yin ve Yang felsefesi ise İÖ 3. Yüzyıl gibi ortaya çıkacaktır. Ancak bu makalenin temeli Gılgamış Destanı ve etkilerini anlatan David Damrosch'un eseri üzerine eleştirel bir bakış olduğundan Yin ve Yang felsefesine bu makalede yer verilmeyecektir. Antik Yunan Dünyası'nın, Martin Bernal'in Black Athena: The Afroasiatic Roots of Classical Civilization (Kara Athena: Klasik Medeniyet'in Afro-Asyatik Kökleri) adlı eserinde İÖ 2. Milenyumda Mısırlılar ve Fenikeliler tarafından Yunanlıların kolonileştirildiğini ve bu yüzden Yunan Kültürünün özellikle Levanten olduğunu ve Mısır ile Sami Kültürlerinin etkilerinin bir karışımı olduğunu belirtmektedir. Eski Asur ve Babil medeniyetlerinin dili olan Akkadça ile yazılan Gılgamış Destanı'nın etkisinin zaten diplomatik dilde Akkadça çivi yazısı kullanılan Antik Mısır üzerinde tesiri olduğu bilinmektedir. İşte yankılanması batıda muhtemelen Mısırlılar ve Fenikeliler ile yoğun ticaret halinde olan Yunanistan'da daha sonra olacak olan bu düşünce, Antik Sümer'de hayat bulmuştu bile (Müller, 2015).

Gılgamış Destanı'nda estetik bir kaygı ile bir araya getirilmiş olan iki zıt karakter yani Gılgamış ve Enkidu bütünlüğü ve mükemmelliği simgeler. Zıtlıklar iki insan karakterine bürünmüştür: Enkidu el değmemiş vahşi doğayı simgeler. Gılgamış da amansız ve acımasız insan uygarlığını temsil etmektedir. Biri olmadan diğeri tanımlanamaz veya herhangi bir anlam taşıyamaz, ancak ve ancak iki farklı gücün bir araya gelişiyle güçler dengelenecektir. Böylesine tarafları uzlaştıran, eksikliğinde tenakuzun mümkün olmadığı bir çatışma, doğu ve batı ile yani şark ve mağrip ile ilişkilendirilebilir. Dolayısıyla, Doğu ve Batı halklarının ve ırklarının çatışmalarının kökeninin bu edebî destana kadar uzandığı çıkarımı yapılabilir. 
Uruk Şehrinin çetin Kralı olan Gılgamış, sonsuz gücünü kötüye kullanmaktadır: "Gılgamış Uruk'un hükümdarı olarak tanıtılır; ancak çok geçmeden hükmü kabul görmemeye başlar. Zira genç erkekleri emri altına alıp, kızları da sarayına götürmektedir" (Arnolt, 2009). Enkidu, Kral'ın bu kuvvet politikasına karşı bir denge oluşturmak için Tanrılar tarafindan gönderilmiştir. Öte yandan Gılgamış, bir şeylerin ters gideceğini sezmesine rağmen olacakları tam olarak kestirememektedir. Bu esnada, tapınaktan Tanrıların izni ile, her yanı saçlarla örtülü olan vahşi Enkidu'yu evcilleştirmek, onu medeni bir adam yapmak için bir fahişe gönderilir:

Şamhat belini sarmalayan kumaşı çözdü,

Avretini sergiledi, Enkidu'nun aklı gitti.

Kız ürkmedi, kokusunu içine çekti:

Kiyafetlerini saçt1, Enkidu üstüne uzandı.

Onun için kadınlık görevini yaptı,

Tutku ile sarı sarmaladi onu.

Altı gün ve yedi gece boyunca

Durulmadı Enkidu, birleşti Şamhat ile (Damrosch, 2007, s.201).

Yaşadığı cinsel tecrübe ve kaybettiği bakirliğinin, yani saflığının ardından, büyük ihtimalle Şamhat'ın ona öğrettiği üzere (eserde bu kısımlar tam anlaşılır değil zira kitabeler kayıp veya okunmaz hale gelmiştir) Enkidu çok geç olmadan bu kötü Kralı yani Gılgamış’’ durdurması gerektiğinin farkına varır. Tam Gılgamış sözde nikâh hakkını elde etmek için diyardaki yeni gelin olmuş kızlardan birinin evine girmek üzereyken Enkidu bu ahlâksızlığı önlemek için onun yolunu keser. Aralarında çok şiddetli bir dövüş başlar. Öyle ki her yumruk ve itiş kakışta tüm şehir beşik gibi sallanır. Dövüş esnasında nedendir bilinmez Gılgamış birden Enkidu'ya bir yakınlık hisseder ve ona sarılır. Böylece, Enkidu ve Gılgamış, birbirine çarpan iki sarkacın tamamen durması gibi, uzlaşmanın çatışmayı yok ettiği o noktada bir olurlar. Bu olay, doğadan gelen bir nevi Panteist bir Enkidu'nun amansız Gılgamış’ı adalet ve merhamet duyguları ile etkilemesini temsil eder. $\mathrm{Bu}$ ikili artı yoldaş olduktan sonra, sedir ağacı odunu toplamak için sedir ormanlarına uzun bir yolculuğa çıkmaya karar verir. Burada zalim canavar Humbaba yaşamaktadır. İşin aslı, bu değerli odunları toplayabilmek için, koruyucu Humbaba’yı 
alt etmek zorundadırlar. Sonunda Humbaba bu meydan okumayı kabul eder ve çetin bir savaşın ardından Enkidu ve Gılgamış Humbaba'yı öldürmeyi başarır. Damrosch bu noktada Saddam Hüseyin'i Humbaba'ya benzetir. Humbaba gaddar bir varlıktır; ama nihayetinde mağdur edilip öldürülmüştür.

2003'ün Ocak ayında, haftalık olarak çıkan Mısır gazetesi Al-Raham, Kahire Amerikan Üniversitesinde görev yapan siyaset bilimcisi Sharif Elmusa'nın bir makalesini yayınladı. Makalede Saddam Gılgamış’a değil, Sedir Ormanı'nın koruyucu iblisi Humbaba 'ya benzetiliyordu. Elmusa'nın benzetmesine göre, zalim Gılgamış’a benzetilmesi gereken kişi George W. Bush idi. Saddam, tıpkı Humbaba gibi, ülkesinin doğal kaynaklarını ele geçirmek isteyen yabancılar tarafından saldırıya uğramıştı. Elmusa yazısında şunlara yer vermişti: "Eski çağlarda kereste, üzerinde herkesin gözü olan bir kaynaktı. Tapınakların, sarayların, evlerin inşasında, mobilya yapımında, tekne imalatında ve yakıt olarak kullanılırdı. Şimdilerde modern, teknolojik uygarlıkların can damarı olan şey ise petrol. Birleşik Devletler ucuz petrolün adeta bağımlısı... Petrol, bu operasyonların as1l amacidır." (Damrosch, s.266).

Esasında Saddam'ın canavarlaştırılması bir nevi Edward Said'in belirttiği gibi garbın şarkı garp romanlarında icat etmeleridir (Kültür ve Emperyalizm,1994). Kültür ve Emperyalizm adlı eserinde bahsettiği gibi, aslında Batının misyonu Şark insanına medeniyeti getirmektir. Onlar (Şarklılar), Batılılar gibi olmadıkları için yönetilmeyi hak etmektedirler. Elbette bu tür bir dayatma karş1sında, Saddam'ın ya da Humbaba'nın sergileyeceği gibi bir direnç kültürü ortaya çıkacaktır. Elbette bu direnç otoriteyi sarsacağından gücün devamı ve sistemin ayakta kalabilmesi için bir şekilde Humbaba tıpkı Beowulf adlı eserdeki Grendel gibi canavarlaştırılacak ve insanlığın devamı için bir tehlike olarak gösterilecekti. İşte Saddam Hüseyin'e yapılan da Damrosch'a göre bir nevi önce onu ortaya çıkarmak, sonra onu güçlendirip, ardından ötekileştirerek yok etmek olacaktı. Bu da Gılgamış Destanı'nın günümüze uyarlandığında ortaya çıkan ironi olabilirdi pekâlâ. Hikâyemize geri dönecek olursak, Sedir ormanlarında elde edilen muazzam galibiyetin ardından, Enkidu ve Gılgamış kutlama yapmak için Uruk Şehri'ne geri dönerler. Zafer kutlamaları esnasında, Tanrıça İştar Gılgamış’ı görür ve ona oracıkta âşık olur. Gılgamış ise, artık tamamen ve ahlaken gelişmiş bir kahraman olmasına rağmen, onu geri çevirmekle kalmaz, bir de rezil eder: 
Kocan Tammuz ile birlikteliğin ebedi değil miydi? Sahi, Allallu kuşuna ne oldu? Hele sana bu cilvelerinin sonucunu anlatayım. Tammuz senin yüzünden ağlıyor, ona yıllar sürecek 1stırap verdin. Rengârenk Allallu kuşu, hani şu sevdiğin, sonra da kanadını kırıp ezdiğin, ormanda oturmuş: 'kanadım' diye haykırıyor! Sen bir aslanı da sevmiş idin. Güçlü, kuvvetli. Yedi, evet yedi kere tuzak kazdın ona. Sen bir atı da sevmiş idin. Savaşlarda ünlenmiş. Ona gem vurup, mahmuz ve kırbaçla onu on dört fersah koşmaya zorlamadın mı? At yorulup da su içmek istediğinde, onu zorlamaya devam edip, annesi Si-li-li'yi ağlatmadın mı? Sırf seni memnun etmek için önünde tütsüler yakan, her gün kuzular kesen bir çobanı da sevmiş idin sen. Onu lanetleyip bir kaplana çevirdin ki kendi evlatları onu kovalasın, ardından kendi köpekleri parça parça etsin. Sen, babanın bahçıvanı olan, sofranı her gün mahsulünün en lezzetlisi ile donatan bir çiftçiyi de sevmiş idin. Gözlerini ona dikip de aklını çelmek için şöyle demiştin: 'Ey çiftçi, bırak da erkeksi gücünü tadayım. O ellerinle bekâretimi al benden'. Ama çiftçi sana demişti ki: 'Senin ağzın ne der? Sen daha hamsın, yiyemem... (Arnolt, 2009)

Bu kabul edilemez küçük düşürme karşısında İştar öfkelenir ve diğer tanrıları Cennetin Boğalarını gönderip Gılgamış ile savaştırmaları konusunda ikna eder. Ölümcül bir savaşın ardından Gılgamış ve Enkidu Cennetin Boğalarını öldürmeyi başarır. Gılgamış boğalardan birinin bacağını kesip İştar'a firlatır. Bu büyük hakaret, Enkidu'nun zamansız ölümü ile sonuçlanacaktır. Tanrılar Enkidu'nun kaderini çizer ve ölümüne karar verirler. Enkidu'nun ölümünün ardından Gılgamış, onulmaz bir isteğe kapılır: Ölümsüzlük. Ölümsüzlüğün sırrına erişmek için, bu sırra vakıf olduğu söylenen Utnapiştim'i bulmak üzere bir yolculuğa daha çıkar. Gılgamış Destanı'nın George Smith tarafından çevrilmiş olan bu kısmı, kendisine dünya çapında ün kazandırmıştır. Bu kısım, ölümsüz olan ve bir büyük tufan esnasında ona gemi yapmayı öğreten Ea tarafından kurtarılan Utnapiştim'i anlatmaktadır. Nuh Tufanı ile Utnapiştim Tufanı arasındaki benzerlikler, İncil ve Gılgamış Destanı arasındaki benzerliklere dair büyük tartışmalara yol açacaktır:

Gılgamış Destanı, Richard Bulliet'in 'İslam-Hristiyan Uygarlığı' adını verdiği büyük ailenin temelini güçlü bir şekilde resmetmektedir. Gılgamış ve İlyada, İncil ve Kur'an birbirinden uzak ve sonsuz çatışma içinde olan toplumların birer ürünü değil, batı Asya ve doğu Akdeniz dünyasının kültürel matrisinin ortak birer sonucudur. İshak ve İsmail üvey kardeşlerdir. Utnapiştim ile Nuh ise birbirine daha yakındır. Onlar tek ve aynı karakterin iki farklı sürümüdür. (Damrosch, s.265) 
Damrosch'un da yansıttığı gibi, metinler arasındaki benzerlikler bugün var olduğu gibi antik çağlarda da var olmuştur. Northrop Fryre, Eleş̧tirinin Anatomisi (2015) adlı eserinde küresel bir edebiyatın mantıksız bir biçimlenim olmayacağını; ama kendi doğası ile uyumlu olmak koşuluyla okunması gerektiğini belirtmiştir. Dolayısı ile edebiyat, ulusal bir eser olmaktan çıkıp küresel bir eser olma yoluna girer. Tipkı Sir James George Frazer'ın Altın Dal (2017) adlı eserinde ilkel kavimlerin ve antik çağ insanlarının folklorları, büyüleri ve dinlerinin mukayeseli bir biçimde analiz edildiğinde, Hristiyanlık inancının kanısı, batılları ve tabuları arasındaki benzerliklerin ortaya çıkması gibi, Gılgamış Destanı'nın da anlattığı ölümsüzlük arayışı, zıt güçlerin birbirini dengeleyip yok etmesi gibi temalar Batı düşünüşünü de derinden etkilemiştir. Özellikle ölümsüzlük arayışı, Batı Simyac1lığının ve Okült felsefesinin temeli olup, İskandinav ve Yunan mitolojilerinin ${ }^{1} \mathrm{de}$ temelini oluşturmuştur.

Öte yandan, gerekli çeviriyi yapsa da George Smith'in talihsiz ve zamansız ölümü, ününden bir şey eksiltmemiştir. Aksine ölümünün ardından ünü dünya çapında yayılmaya devam etmiş̧ir. Günümüzde halen, Gılgamış Destanı ile Kutsal Kitaplar arasındaki benzerliklere dair tartışmalar sürmektedir. Gılgamış'ın bu yolculuğu, ölümsüzlüğün çaresini bulamadığı için hüsranla sonuçlansa da Utnapiştim Gılgamış’ın denizin dibinden ölümsüzlüğü sağlayan bir bitki koparmasına izin verir. Hiç tereddüt etmeyen Gılgamış, ayaklarına ağır kayalar bağlar ve suya dalar. Canlıların sonsuza kadar genç kalmasını sağlayan bu bitkiyi bulur, bu bitkinin bir benzeri Yunan mitlerinde tanrıların yiyecek ve içecekleri olan Ambrosia ve Nektar, İskandinav Mitolojisinde ise ölümsüzlüğün anahtarı tanrıça Idun’un altın elmalarında göze çarpar. Ne var ki hikâyenin devamında bir yılan gelip bitkiyi Gılgamış’tan çalar. Tüm bu ölümsüzlüğün peşindeki görevler için, ataerkil toplumlardaki kardeş dayanışması ve destansı görevlerin ilk örnekleri demek yanlış olmaz. Zira benzeri durumlar Yunan Orpheus ve Urydike mitinde ve İskandinav Ölümsüzlüğün Elmaları mitinde tekrarlanmaktadır. Dolayısıyla Damrosch, G11gamış Destanı ile karşımıza çıkan efsanelerin çok benzerlerinin daha sonraları batı mitlerinde görüldüğünü yansıtmıştır.

1 Yunan Mitolojisinde Odisseas ölümlüler dünyasına inerek ölümsüzlüğü anlamaya çalışmıştır, Zeus baş tanrı olmasına rağmen oğlu Herkül'ün ölümüne çare bulmaya çalışmış, tanrılar Ambrosia ve Nektar yiyerek ölümsüz olabilmişlerdir. Benzer hikayeler İskandinav efsanelerinde de vardır. Tanrılar ölümsüz olmayı sağlayabilmek için Tanrıça Iðunn'un altın elmalarına ihtiyaç duyarlar. 
Gömülü Kitap adlı eserde detaylı olarak ve kesin kanıtlarla gösterilmiş başka bir durum ise Hormuzd Rassam² ile batı arasındaki çelişkidir. Başka bir deyişle, ötekilik ve aynılık durumları bu kısımlarda iyi örneklendirilmiştir. Mağrip olmak kendinden olmayanları hiçe saymak demek olduğundan, Rassam'ın ortaya çıkardığı her şey bir kalemde silinmiştir. Damrosch eserinde şöyle demiştir:

Her halükârda, bir inanç sistemi derinlemesine oturduğu vakit, bugün bilişsel uyumsuzluk adı verilen mekanizmadan tam destek görür. İnsanlar görmeyi istedikleri kanıtları ararken, karşıt kanıtları küçümser, hatta tamamen görmezden gelirler. Bilhassa da geleceğe dair öngörüler bu eğilime açık konumdadır. Gerçekleşen olaylar seçici bir şekilde kehanet ile ilişkilendirilir, üzerinde durulur veya durumuna göre görmezden gelinir. (Damrosch, s.171)

Batı ekseriyetle Doğu ve doğulu imgesini kendi kurgusuyla yaratmaya çabalamıştır. Büyük İskender'in seferlerinden bu yana Doğu daima gizemli, egzotik ama bir o kadar da eğitilmesi gereken barbarlar olarak görülmüştür. Bat1, Doğu'yu kontrol etmeye çalışırken bunu dil, din ve kültür açısından kendi bildiklerini doğru sayarak karşıya ne biliyorsa onu öğreterek aydınlatmaya çalışmış ve kendi gördüğünü herhangi bir alternatif teamül kabul etmeden gerçek ve doğru varsaymıştır. Gerçeklerden uzak bir şekilde değerlendirme yaparken

"[k]urgusal bir oluşturu olan imgeyi değerlendiren de bir bakıma imgeyi yeniden kurgular. Dolayısıyla, imgenin değerlendirilmesinin de kurgusal olduğunu belirtmek gerekir... Ortak belleğe yerleşen ve böylece giderek olağanlaşan ve sorgulanmaz yargiya, daha doğru bir anlatımla önyargıya dönüşen imgeler, düşünsel ve sanatsal yaratım alanlarına da yansırlar." (Kula, 2011, s.3)

Bu örneğin en çarpıcı biçimlerinden biri Joseph Conrad'ın Karanlığın Yüreği (2011) adlı romanında görülmektedir. Evrimin maymunlarla insanlar arasındaki kayıp zincirini keşfetmiş edasıyla ritüel halindeki Afrikalıları gören ve onların da insan olduğu çıkarsamasını yapan Marlow’un bahşetmiş olduğu bu lütuf, Batı'nın uzun süre kendinden olmayana yönelttiği bakış açısıdır. En nihayetinde bugünkü modern Ampirik bilginin ilkel adımlarını ortaya çıkaracak olan Aristoteles, yani Batı'nın merkeze yerleştirdiği filozof olan Aristoteles, iki tür insan olduğunu söylememiş midir? Bunlardan biri Helenler, diğeri ise Barbarlardır; yani

2 Asur uygarlığı üzerine ilk ciddi çalışmaları yapan arkeologdur. Aslen Süryani’dir. Bilinen ilk Osmanlı ve ilk Orta Doğulu arkeolog olduğu genel kanıdır. 
Yunanlılar dışında kalanlar. Aynı Aristoteles'e göre birileri yönetmeli ve diğerleri yönetilmelidir; zira kölelik doğaldır. İşte Rassam'ın maruz kaldığı da tastamam bundan ibarettir. Hristiyan bir Arap olan Rassam, zamanının ilk bilim insanlarından biri olarak gösterilebilir. Asur Banipal'in kütüphanesini keşfeden o olsa da bu keşfi hak ettiği övgüyü almamış, ardından bu keşif tamamen George Smith ${ }^{3}$ 'e mâl edilmiştir. Rassam'ın bu kütüphaneyi keşfettiği sırada George Smith'in daha 17 yaşında olması bu durumu geçersiz kılmaktadır. Batının böyle bir keşfi kabullenememesi üzerine, Arap bir bilim adamının keşfi Smith'e atfedilmiştir. Başka bir husus da George Smith'in Suriye, Irak ve Osmanlı İmparatorluğu'na yabanc1 oluşudur. Arapça veya diğer yerel diller hakkında bir bilgisi yoktur. Bu bağlamda olayları yorumlaması, Rassam'ınkinden farklıydı. Smith vukuatları çabuk değerlendirmede, gelişmeleri ve Osmanlı Memurlarının 'taleplerini' anlamaktan yoksun olduğu için, çoğu zaman bu memurların işini zorlaştırmak için ona engel olduklarını sandı:

Tüm ufak rahatsızlıklar ve zaman zaman karşıma koyulan çocukça engellere rağmen, tüm içtenliğimle söyleyebilirim ki, Osmanlılar genel olarak iyi huylu, nazik ve yardımsever insanlardır. Ve bildiğim kadarıyla, tüm memurlara minnet borcum var. Zaman zaman keşiflerimde bana engel olmuş olsalar da, gördüğüm şey çoğunlukla nezaket ve yardımdan ibaretti. (Damrosch, s.108).

Ancak ne yazıktır ki Osmanlı Memurları, yapılan bu kazıların ve gün yüzüne çıkarılan yazıtların esas değerini anlayamıyordu. Onlar için bu yazıtlar altın, gümüş, bakır vb. değerli metaller içermedikleri sürece kil ve tozdan ibaretti. Buna karşılık olarak, Smith de yerel halkın doğasını anlamıyordu. Rassam bu insanların ihtiyaç ve taleplerine yanıt verebiliyor, onlar tarafindan seviliyordu. Bu sevginin, Rassam'ın Britanya'ya karşı takındığı tavırdan geldiği sanıldı. Dahası, Rassam'ın kimliği üzerine birçok komplo teorisi üretilmişti. Hain olmakla suçlanmıştı. Çift taraflı çalışan bir ajan olup Şarka hizmet ettiği söylenmişti. Ona karşı yapılan en iyimser eleştirilerde bile onun ilham verici olmadığından dem vuruluyordu. Rassam'ın Layard'dan ilham aldığını, Austen Henry Layard ${ }^{4}$ olmasa Rassam'ın bu keşifleri yapamayacağını iddia ediyorlardı. "Viktoryalılar'ın Şark insanını pasif ve kadın tabiatlı görme

3 George Smith, Asuroloji biliminin öncülerinden olan İngiliz Asurolog ve arkeolog. 1870'li yıllarda Gılgamış Destanı'nın ilk modern çevirisini yayımlamasıyla bilinir

4 Austen Henry Layard (1817-1894) bir Britanyalı gezgin, arkeolog, çivi yazısı uzmanı, sanat tarihçisi, teknik ressam, koleksiyoncu, yazar ve diplomatt1 
eğilimi vardı. Öyle ki, Rassam'ı işleri için motive eden şey Layard'ın İngiliz enerjisinden başkası olamazdı.” (Damrosch, s.113). Rassam ve İngiliz Müzesi arasındaki dalgalanma, Doğu ile Batı arasındaki asla durulmayan dalgalanma olarak da görülebilir. Gılgamış Destanı'nı günümüzde okunabilir kılan etkenlerden biri de insanların A.B.D gibi batı güçlerine karşı mücadele veren Humbaba'ları görebilmesidir. Gılgamış bir zamanlar gücünü kötüye kullanan bir zorba idi. Damrosch, destanda yaşanan olayları batının günümüzdeki politikaları ile ilişkilendirir. Damrosch'a göre Gılgamış Destanı günümüzde sıklıkla ölüm korkusu ve ölümsüzlük üzerine olan bir varoluşçu hikâyesi olarak okutulur. Ancak destan bir o kadar da zalimlik ve bunun sonuçları üzerinedir (Damrosch, s.203).

Kitabının sonuna dek, Damrosch kadim zamanlardan günümüze ulaşan Asur Banipal ile Sümer mirasının önemi üzerinde durmaktadır. Dahası, doğu ile batı arasındaki bu yıkıcı mücadele tıpkı bir lanet gibi Doğu Akdeniz ülkelerinin peşini bırakmamıştır:

Mezopotamya'da tekerrür eden bir problem olan seller, toptan yıkımın simgesi haline gelmişti. Büyük seller güney Mezopotamya düzlüklerindeki kerpiçten yapılma şehirleri yok edecek güçteydi. Kraliyet annalları şehre yapılmış olan büyük saldırıları bile sel olarak resmediyordu. Örneğin Senakribin M.Ö. 689 yılında Babil'i alması bir sel olarak resmedilmişti. (Damrosch, s.221)

Seller veya düşman ordularını simgeleyen değişmeceli seller bir kültürü tamamen yok ettikçe, Damrosch bu dev sahnenin ardındaki dertli adamı tespit etti. Bu kişi Banipal'ın babası idi. Kendi kendine konuşan bu adam kendi asaletinde kaybolmuştu: "Ben güçlüyüm, ben devasayım, ben heyulayım, şerefliyim, en büyük benim, tüm krallar arasında eşim benzerim yok" (Damrosch 2007: 173).

Bir başka çarpıcı husus da kral ve prenslere konuşma ve yazma öğretilmemesiydi. Zira bu yükü onların yerine taşıyacak olan başkaları vardı. Banipal bir istisna olsa da ataları ondan önce bu geleneği sürdürmüşlerdi. "Nasıl günümüz başkanlarından kendi konuşmalarını yazmaları beklenmiyorsa, o vakitler krallardan okuma yazma bilmeleri beklenmiyordu. Bunun sonucu olarak, kraliyet müfredatında okuma yazma dersleri çok nadir olarak görüldü” (Damrosch, s.197).

Doğruyu söylemek gerekirse Doğu ile Batı arasındaki dalgalanma günümüzde halen varlığını sürdürmektedir ve gelecekte de sürdürmeye devam ede- 
cektir. Samuel Huntington, Medeniyetler Çatışması ve Dünya Düzeninin Yeniden Kurulması adlı eserinde uygarlıkların insan kabilelerinin nihai hali olduğunu ve uygarlık çatışmalarının kabile savaşlarının evrensel boyuttaki halleri olduğunu ileri sürmektedir. Kadim yazılardan da açıkça görüldüğü üzere insan ırkı aynı veyahut benzer köklerden yürümüştür. Gılgamış ve İlyada gibi meşhur Destanların binlerce yıl önce meydana gelen ortak olaylardan esinlenerek yazılmış olmaları mümkündür. Tanrıların yazgısı ile Gılgamış da Aşil de uzak diyarlara yolculuk etmişlerdir. Bundan da öte, ikisinin de kaderi yalnızca tanrılara karşı verdikleri mücadele bakımından değil, bir diğer imtihanları olan gururları bakımından da benzeşmektedir. Tüm bu elimizdekiler ışığında, her ne kadar bir alıntı ile kritiği bitirmek çok yaygın olmasa da, Damrosch'un bu ilginç çalı̧̧masından bir sonuca varmaya çalışırsak, Martin Bernal'ın tarihe dair şu sözleri ile bir nihayete varmak uygun olacaktır: “[...]mevcut ve kısa vadeli istisnalara rağmen, günümüzde ırkların biyografisi olarak görülen tarih aslında güçlü ve sağlıklı insanların zayıf ve çelimsizlere karşı üstünlüğünden ibarettir” (Bernal, 2003, s.32). 


\section{Kaynakça}

Arnolt, W. M. (Trans.). (2009). Gilgamesh: The Oldest Epic Tale [Kindle].

Arslan, A. (2006). İlkçă̆ Felsefe Tarihi (8.bask1). İstanbul: İstanbul Bilgi Üniversitesi.

Bernal, M. (2003). Black Athena: The Afroasiatic Roots of Classical Civilization (The Fabrication of Ancient Greece) 1785-1985. New Brunswick, NJ: Rutgers Univ. Press.

Conrad, J., \& Yücesoy, E. (2011). Karanlı̆̆ın yüreği: Uzun öykü. İstanbul: Can Yayınları.

Frazer, J. G. (2017). Altın Dal-Dinin ve Folklorun Kökleri (M. H. Doğan, Çevir.). İstanbul: YKY.

Frye, N., \& Koçak, H. (2015). Eleştirinin Anatomisi: Dört deneme. İstanbul: Ayrıntı Yayınları.

Huntington, S. P. (2017). Medeniyetler Çatışması ve Dünya Düzeninin Yeniden Kurulması. İstanbul: Okuyan Us Yayın.

Kula, O. B. (2011). Batı Edebiyatında Oryantalizm. Beyoğlu, İstanbul: Türkiye İş Bankası.

Mark, J. J. (2018, July 03). Gilgamesh. Retrieved from https://www.ancient.eu/gilgamesh/

Müller, Matthias, 2015, Akkadian from Egypt. In Julie Stauder-Porchet, Andréas Stauder and Willeke Wendrich (eds.), UCLA Encyclopedia of Egyptology, Los Angeles. 